\title{
Study of Energy Saving and Emission Reduction based on the OLAP Multi-Indicator Relational Model
}

\author{
Y. S. Shen ${ }^{1}$, Z. F. Tan ${ }^{1}$, X. L. Shen ${ }^{2}$, J. J. Bai ${ }^{2}$, Q. Z. $\mathrm{Li}^{2, *}$ and S. Wang ${ }^{3}$ \\ ${ }^{1}$ Department of Technical Economy and Management, North China Electric Power University, Beijing, 102206, China \\ ${ }^{2}$ Department of Control and Computer Engineering, North China Electric Power University, Beijing, 102206, China \\ ${ }^{3}$ Faculty of Engineering and Applied Science, University of Regina, Regina, SK S4S 0A2, Canada
}

Received 9 October 2011; revised 25 May 2012; accepted 21 June 2012; published online 27 September 2012

\begin{abstract}
The research related to energy-saving and emission-reduction can be helpful in designing the energy-saving development mode. The conventional methods for energy-saving and emission-reduction usually take a long time to estimate the effects under different modes, and their estimations may have many errors with long-term economic and environmental impacts. The environmental protection and economic development are interrelated with each other; a balanced development has to be taken into account synthetically. Since the relationship between economy and environment is complex, this paper studies the effects of the two indicators, and identifies their key impact on achieving energy-saving and emission-reduction. This paper conducts a thorough study on the economic and environmental developments in Beijing based on the OLAP multi-indicator relational model. The relation quantization function can be obtained and the energy-saving and emission-reduction from the perspective of the quantitative multi-indicator relationship can be studied in this study.
\end{abstract}

Keywords: energy-saving and emission-reduction, multi-indicator relationship, OLAP, coordinated development

\section{Introduction}

This study creates a multi-indicator relational model based on the On-Line Analysis Processing (OLAP) technology, and uses an example for analyzing the relationship between environmental pollution and economic development system. The model's application is introduced in detail. The OLAP is an information technology, which can conduct single-level dimensional and multi-level dimensional data analysis.

In recent years, there has been a considerable progress in the study on the energy-saving and emission-reduction technology, which mainly includes three aspects: (i) the comprehensive energy-saving and emission-reduction plan has been published, and the research and promotion of the technology have been programmed macroscopically; (ii) The energy-saving technology based on an industrial platform has begun to take shape; (iii) a government-led and business-oriented pattern has been formed (Zhang et al., 2010). Currently, information technology has become a powerful tool for energysaving and emission-reduction. Many technologies can help to improve resource utilization ( $\mathrm{Li}$ et al., 2011), to save energy (Fang et al., 2012), to reduce production costs (Schoots et al.,

\footnotetext{
* Corresponding author. Tel.: +86 10 61772480; fax: +86 1061772480.

E-mail address: liqiangzhi1988@126.com (Z. F. Tan).
}

ISSN: 1726-2135 print/1684-8799 online

(C) 2012 ISEIS All rights reserved. doi:10.3808/jei.201200225
2008), and to create a systematic energy- saving and emission-reduction project (Ouyang et al., 2011). However, few studies focus on using information technology to achieve a balanced development synthetically. Thus it is important to study the effect of the relationship between economy and environment.

To design and build foundation of the models-research platform, this paper studies the relationship of the two systems and selects the system which can reflect its status. In this study, the system of indicators was developed (Shen et al., 2010). The relational model of the research system was transformed into the relationship between the internal multiindicators of a set of two indicators. A variety of tools and technologies were applied to build the analysis model, including the statistical analysis of the OLAP technology and mathematical tools. This study created a 3E (Energy- Economic-Environ- ment) decision support platform based on the data warehouse which is comprised of of system indicator data (Liu, 2008). The OLAP technology and mathematical statistics analysis tools were integrated in order to provide a solid foundation of the relationship between the building and the research of the model.

To build the analysis model for the multi-indicator relationship based on the OLAP technology and mathematical statistics, the study mainly uses a combination of qualitative constraints and quantitative precise (Zhang, 2010). Data would be preprocessed first. Then the indicator relationship which has obvious influence relations would be filtered out. 
At last the correlation matrix came out (Wang, 2010), which would be used for the preparation of further quantitative precise analysis. Based on the analysis of the effects of statistical methods on the relationship between indicators of the correlation matrix, this study provided an accurate quantitative analysis, chose the mathematical statistics with the smallest error, and used the expression of the matrix function to generate the results.

The focus of energy-saving and emission-reduction is the economy effect on both energy and environment (Liu et al., 2012a). In this paper, the effects relationship between economy and environment in Beijing was used as an example to make a detailed introduction of the model application. According to the selection principle of the metadata indicators, a indicator system was chosen to quantify the effect of economic development on energy consumption (Shaligram, 2007).

\section{OLAP Multi-Indicator Relational Model}

To study the relationship between economy and environment, this paper builds two sets of indicators to describe the economic and environmental systems and analyzes their relationships. Firstly, according to the OLAP technology, this paper studies the impact of all indicators of the economic system set on each indicator of the environmental system set. Secondly, the qualitative analysis on the impact relationship is given in this study. Then, this paper provides the impact relational curves, preprocesses the data, and gives the correlation matrix between the indicators. Finally, this paper uses the statistical method to analyze the indicator value, and provides the quantitative relationship matrix functions (Bouwman, 1983). The specific process is shown in Figure 1.

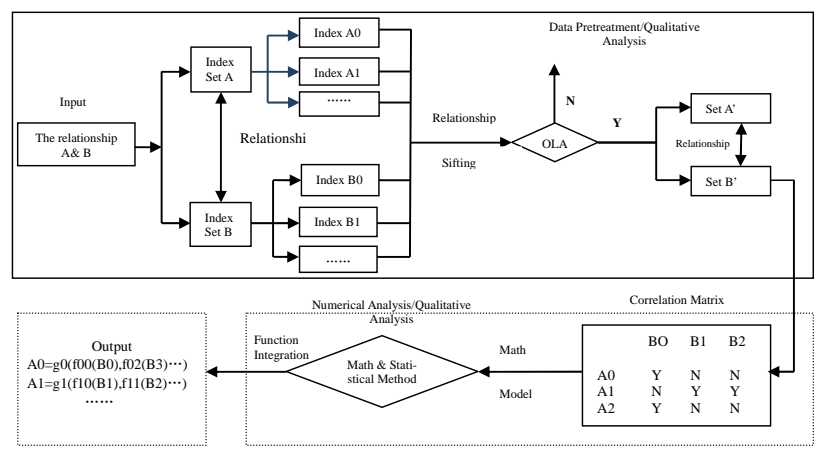

Figure 1. The analysis process chart of multi-indicator relationship.

\subsection{Basis of Model Development}

To build the OLAP multi-indicator relational model, a variety of tools and techniques were used, including the OLAP technology and mathematical analysis tools such as SPSS (Yin and Liu, 2003) and MATLAB. To study the relationship between economy and environment, this study builds 3E decision support platform which is comprised of 3E data warehouse, various data analysis tools (Wang et al., 2009c), and $3 E$ application study.

\subsubsection{Introduction of 3E Decision Support Platform}

In this paper, the guiding ideology of building $3 \mathrm{E}$ decision support platform includes the focus of the 3E sustainable development (You et al., 2011), the integration of Beijing and China Major cities' 3E indicator data in ten years (Wang et al., 2009b), the OLAP analysis tools, common computing analysis tools, the latest achievement of scientific research, as well as policies and regulations in the recent years. Figure 2 describes the framework of the 3E decision support platform (Wang and Shen, 2009).

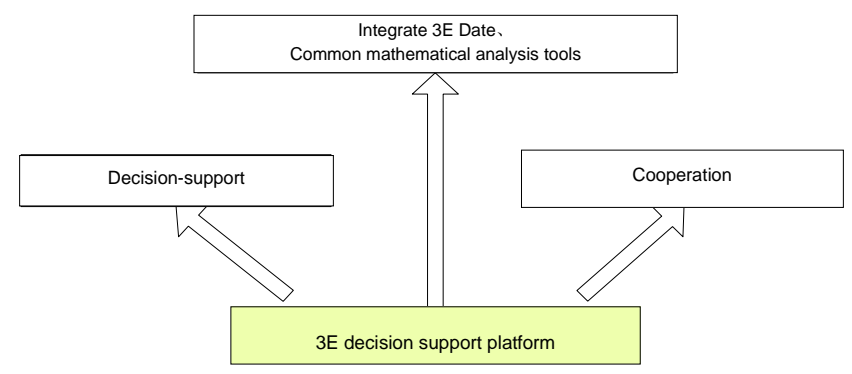

Figure 2. The framework of the 3E decision support platform.

This paper provides a definition for the specific functions of the $3 \mathrm{E}$ decision support platform, including the mathematical computation software, the comparative analysis (Liu et al., 2012b), the OLAP analysis, the prediction and warning (Wang et al., 2009a), and the applied research (Wang et al., 2011a). The specific structure functions of the $3 \mathrm{E}$ decision support platform are shown in Figure 3.

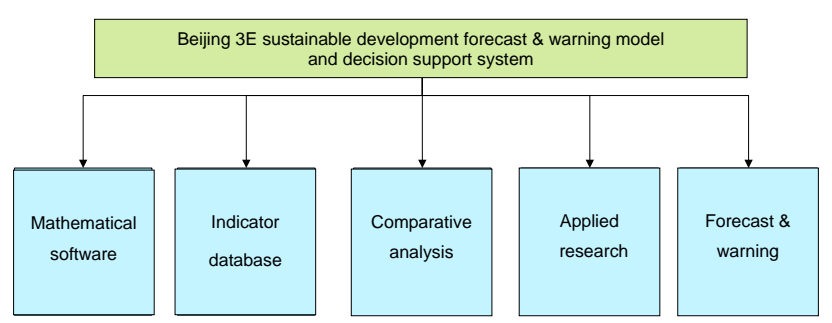

Figure 3. The specific structure functions of 3E decision support platform.

\subsubsection{Achievement of OLAP Multi-Indicator Relational Mo-} del

The introduction of the indicator relational model in this study is mainly based on the integrated OLAP analysis tool (Yang et al., 2010). This paper uses the OLAP technology to conduct a qualitative analysis on the related indicator, creates SQL-Server Database warehouse (Tony and Mike, 2003), and achieves the pretreatment of the research problem. Moreover, a detailed description of the OLAP technology and the specific implementation process are given which is integrated with the platform. The on-line analysis processing can have level dimensional and multi-level dimensional data analysis (Mike and Tim, 2001). The implementation method of the $3 \mathrm{E}$ indicator data relationship can be summarized as the following steps: (i) creating the fact table and the dimension 


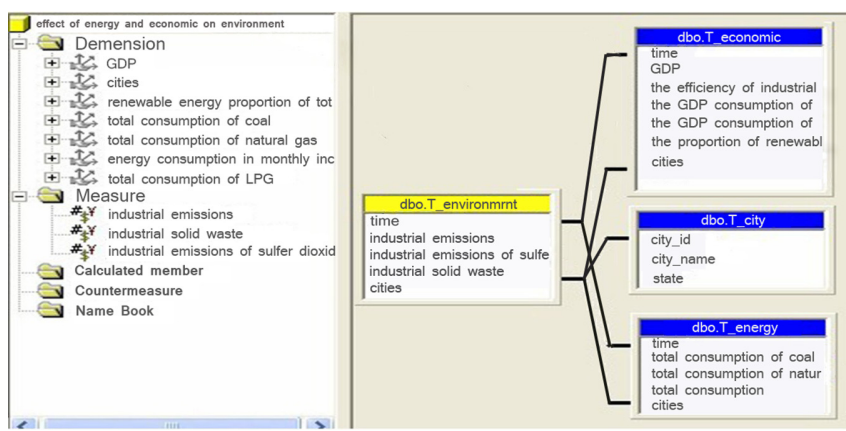

Figure 4. Cubic "the effect of energy and economic on environment" and the map relationship of fact table and dimension table.

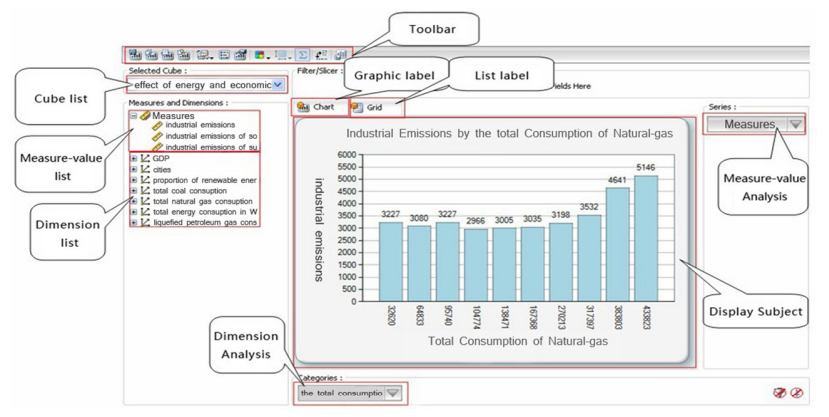

Figure 5. Display of OLAP visualization chart.

table. The fact data represents the numeric data which can be analyzed. It also includes the fact table and the dimension table related to the foreign key. To analyze the relationship of $3 \mathrm{E}$, this study designs the energy, economic and environment as the fact table ( $\mathrm{Lv}$ et al., 2011), the name of the corresponding indicator is a field and includes the two properties of time and city. For example, to analyze the effect of energy and economy on environment, the environment data is used to analyze the target data, which is called measure value; the data of energy and economic is the condition data used to analyze the target data, which is called dimension. This study creates a fact table related to the environment data and three dimension tables in the database. The built environment table (T-environment), the indicator data of the table is the industrial waste gas emission, $\mathrm{SO}_{2}$ emission and solid waste emission. The three dimension tables are the economic table (T-economic), the energy dimension table (T-energy) and the city dimension table (T-city). The structure of economic table includes time, city, GDP, per ¥ 10,000 GDP energy consumption and proportion of the renewable energy of the total energy. The energy dimension table includes time, city, total coal consumption, total liquefied petroleum consumption and total natural gas consumption. The city dimension table includes city logo and city name (Tan et al., 2009); (ii) Creating cube. According to the indicators, total coal consumption, total liquefied petroleum consumption and total natural gas consumption of energy and GDP, 10,000 RMB GDP energy consumption and proportion of the renewable energy of the total energy of the economic may have an effect on the industrial waste gas emission, $\mathrm{SO}_{2}$ emission and solid waste emi- ssion (Wang and Liu, 2011). Thus this study uses the Analysis Services Manager to create six dimensions in the workspace (includng total coal consumption, total liquefied petroleum consumption, total natural gas consumption, GDP, per $¥ 10,000$ GDP energy consumption, and proportion of the renewable energy of the total energy of the economic) and three measure value (including industrial waste gas emission, $\mathrm{SO}_{2}$ emission and solid waste emission). Thus this study creates the cube cubic "effect of energy and economic on environment” (Ma, 2012), and creates the map between the fact table and the dimension table (Figure 4); (iii) Visualization. This study implements the visualization through the VS.NET BI (Figure 5).

This method divides the multidimensional structure of the multidimensional database into the fact tables and the dimension tables. The fact tables are used to store data and dimensional keywords. The dimensional tables are used to store the level and members of the table and other descriptive information of the dimension table. In the correlation analysis of the regional $3 \mathrm{E}$ indicator, the fact table is used to store the target indicator data. The dimension keywords are time and city. The dimension table is used to store the basic indicator data. This study uses the dimension keyword to connect all the links with the fact table, which is called star design.

\subsection{Model Construction}

\subsubsection{Selection of Indicators}

To study the relationship between the two systems, this paper selects the indicators that can reflect the status of the system synthetically, and inputs the data to the $3 \mathrm{E}$ decision support platform. This paper builds the indicators system according to the following principles. Principle of intergraty: the OLAP technology is used for data preprocessing, which is an intuitive way to remove the relationship that has an unobvious influence among indicators; Principle of science: the construction of the indicator system must be strictly in accordance with the scientific meaning of the development in order to form an organic entirety and reflect the real nature of the development objectively. This study collects the highquality and reliable data at a reasonable cost. When studying the quantitative relationship between the two systems, this paper selects indicators to form an indicator system, and then uses the selected indicators to form the indicators collection. For example, when studing the relationship between the two systems of $A$ and $B$, this paper selects the indicator system to construct the indicators matrix of the system:

$$
\begin{aligned}
& A=\left(A_{1}, A_{2}, A_{3}, A_{4}, A_{5}, \ldots A_{\mathrm{i}}\right) \\
& B=\left(B_{1}, B_{2}, B_{3}, B_{4}, B_{5}, \ldots B_{\mathrm{j}}\right)
\end{aligned}
$$

\subsubsection{Process of Qualitative Analysis}

This study sets qualitative constraints to the indicator data through the OLAP technology, makes the two system indicator sets $A$ and $B$ have the two-dimensional matrix Cartesian product, and obtains the correlation matrix $C$, denoted by: 


\begin{tabular}{|l|r}
\hline & MeasureLevels \\
\hline Natural-gas Total Consumption & Industrial Emissions \\
\hline-- Nall the & \\
\hline 32620 & $35,057.00$ \\
\hline 64833 & $3,227.00$ \\
\hline 95740 & $3,080.00$ \\
\hline 104774 & $3,227.00$ \\
\hline 138471 & $2,966.00$ \\
\hline 167368 & $3,005.00$ \\
\hline 270213 & $3,035.00$ \\
\hline 317397 & $3,198.00$ \\
\hline 383803 & $3,532.00$ \\
\hline 433823 & $4,641.00$ \\
\hline
\end{tabular}

Figure 6. Data list.

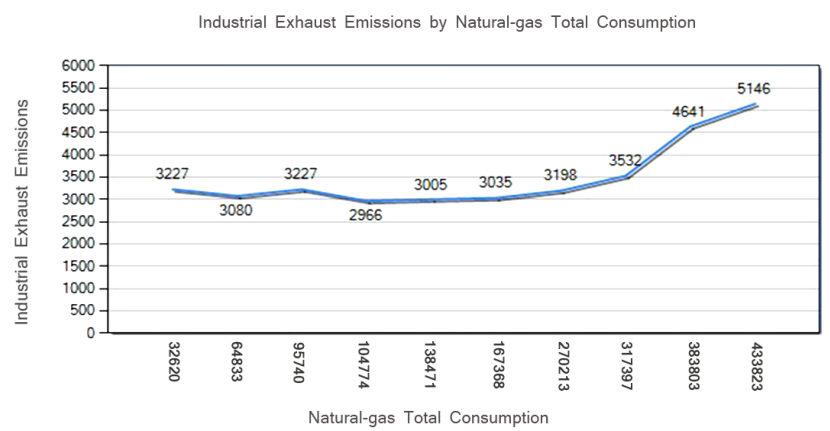

Figure 7. Relationship curve.

Table 1. Correlation Matrix

\begin{tabular}{llllllll}
\hline$A$ & $B_{0}$ & $B_{1}$ & $B_{2}$ & $B_{3}$ & $B_{4}$ & $B_{5}$ & $B_{\mathrm{j}}$ \\
\hline$A_{0}$ & $\mathrm{Y} / \mathrm{N}$ & $\mathrm{Y} / \mathrm{N}$ & $\mathrm{Y} / \mathrm{N}$ & $\mathrm{Y} / \mathrm{N}$ & $\mathrm{Y} / \mathrm{N}$ & $\mathrm{Y} / \mathrm{N}$ & $\mathrm{Y} / \mathrm{N}$ \\
$A_{1}$ & $\mathrm{Y} / \mathrm{N}$ & $\mathrm{Y} / \mathrm{N}$ & $\mathrm{Y} / \mathrm{N}$ & $\mathrm{Y} / \mathrm{N}$ & $\mathrm{Y} / \mathrm{N}$ & $\mathrm{Y} / \mathrm{N}$ & $\mathrm{Y} / \mathrm{N}$ \\
$A_{2}$ & $\mathrm{Y} / \mathrm{N}$ & $\mathrm{Y} / \mathrm{N}$ & $\mathrm{Y} / \mathrm{N}$ & $\mathrm{Y} / \mathrm{N}$ & $\mathrm{Y} / \mathrm{N}$ & $\mathrm{Y} / \mathrm{N}$ & $\mathrm{Y} / \mathrm{N}$ \\
$A_{3}$ & $\mathrm{Y} / \mathrm{N}$ & $\mathrm{Y} / \mathrm{N}$ & $\mathrm{Y} / \mathrm{N}$ & $\mathrm{Y} / \mathrm{N}$ & $\mathrm{Y} / \mathrm{N}$ & $\mathrm{Y} / \mathrm{N}$ & $\mathrm{Y} / \mathrm{N}$ \\
$A_{4}$ & $\mathrm{Y} / \mathrm{N}$ & $\mathrm{Y} / \mathrm{N}$ & $\mathrm{Y} / \mathrm{N}$ & $\mathrm{Y} / \mathrm{N}$ & $\mathrm{Y} / \mathrm{N}$ & $\mathrm{Y} / \mathrm{N}$ & $\mathrm{Y} / \mathrm{N}$ \\
$A_{5}$ & $\mathrm{Y} / \mathrm{N}$ & $\mathrm{Y} / \mathrm{N}$ & $\mathrm{Y} / \mathrm{N}$ & $\mathrm{Y} / \mathrm{N}$ & $\mathrm{Y} / \mathrm{N}$ & $\mathrm{Y} / \mathrm{N}$ & $\mathrm{Y} / \mathrm{N}$ \\
$A_{\mathrm{i}}$ & $\mathrm{Y} / \mathrm{N}$ & $\mathrm{Y} / \mathrm{N}$ & $\mathrm{Y} / \mathrm{N}$ & $\mathrm{Y} / \mathrm{N}$ & $\mathrm{Y} / \mathrm{N}$ & $\mathrm{Y} / \mathrm{N}$ & $\mathrm{Y} / \mathrm{N}$ \\
\hline
\end{tabular}

$A \times B=C$

$$
C=\left\{\begin{array}{cccc}
c_{11} & c_{12} & \cdots & c_{1 \mathrm{j}} \\
c_{21} & c_{22} & \cdots & c_{2 \mathrm{j}} \\
\vdots & \vdots & & \vdots \\
c_{\mathrm{i} 1} & c_{\mathrm{i} 2} & \cdots & c_{\mathrm{ij}}
\end{array}\right\}
$$

As an element of system $B, C_{\mathrm{ij}}$ stands for the degree of the influence of $B_{\mathrm{j}}$ on $A_{\mathrm{i}}$. The model uses the characteristics of the OLAP technology for the qualitative constraints of the indicator data. As shown in Figures 6 and 7, the use of the OLAP tools gets two indicators data list intuitively and the relationship curve. According to the degree of influence in this figure, a value to the elements in $C$ is given, as shown in Table1. If the impact is significant (denoted as $Y$ ) or vague (denoted as $N$ ), this paper presents a correlation matrix set $C$, which makes a preparation for further quantitative accurate analysis.

\subsubsection{Quantitative Analysis}

To carry out the qualitative constraint analysis of the indicator data with the OLAP technology, the study gives us a research direction. After the pretreatment of the use of the OLAP technology for the indicator data, this study uses statistical methods to carry out a quantitative analysis precisely. This study makes an assumption that the influence function is $f_{\mathrm{ij}}$, and the influence function matrix $F$ is:

$$
\mathrm{F}=\left\{\begin{array}{cccc}
f_{11} & f_{12} & \cdots & f_{1 \mathrm{j}} \\
f_{21} & f_{22} & \cdots & f_{2 \mathrm{j}} \\
\vdots & \vdots & & \vdots \\
f_{\mathrm{i} 1} & f_{\mathrm{i} 2} & \cdots & f_{\mathrm{ij}}
\end{array}\right\}
$$

A variety of mathematical models were used in this study. To fit the function by the relationship between the indicators, the smallest error of the mathematical model is selected to obtain the influence function of the relationship between two indicators. This study assumes that the influence weight of different indicators $B_{\mathrm{j}}(\mathrm{j}=1,2, \ldots, \mathrm{j})$ for the same indicator $A_{\mathrm{i}}$ is $r_{\mathrm{ij}}$. Each indicator $A_{\mathrm{i}}$ is corresponding to a longitudinal matrix $R_{\mathrm{i}}$ :

$R_{i}=\left\{\begin{array}{l}r_{i 1} \\ r_{i 2} \\ \cdots \\ r_{i j}\end{array}\right\}$

Let matrix $R$ is:

$R=\left(R_{1}, R_{2}, \ldots, R_{i}\right)$

Let matrix $G$ is:

$G=F \times R$

Then, we have:

$\mathrm{G}=\left\{\begin{array}{cccc}g_{1} & & & \ldots \\ & \mathrm{g}_{2} & \\ & \ddots & \\ \vdots & & \mathrm{g}_{i}\end{array}\right\}$

where:

$g_{i}=\left(f_{i 1}, f_{i 2}, \cdots, f_{i j}\right)\left\{\begin{array}{l}r_{i 1} \\ r_{i 2} \\ \cdots \\ r_{i j}\end{array}\right\}=F_{i} R_{i}=R_{i}^{T} F_{i}^{T}$

$g_{i}$ is the integrated influence function for all indicators of system $B$ on the indicator $A_{\mathrm{i}}$ of system $A$. 
A detailed description of the application of the model to examples of the environmental protection and the economic development is in the following section.

\section{Study of Energy-Saving and Emission-Reduction}

Along with the social development and the increasing attention to the sustainable development, the low carbon development has become an effective way to achieve the economic development. Therefore, how to achieve energysaving and emission- reduction as well as how to develop the economy has become a focus of the research subject. The environmental protection and the economic development are interrelated with each other, it is necessary to take a balanced development into consideration synthetically. Moreover, the indicator relationship between economy and environment is complex, thus this paper studies the effects of these two indicators, and identifies the key impact of indicators in order to achieve energy-saving and emission-reduction. This paper uses an example of the effects of economic development and environment indicators in Beijing.

\subsection{Selection of Indicators}

The selection of indicators mainly follows two principles: the principles of science and the principle of integrity. The selected indicators system of the economic development and the environment status are shown in Figure 8.

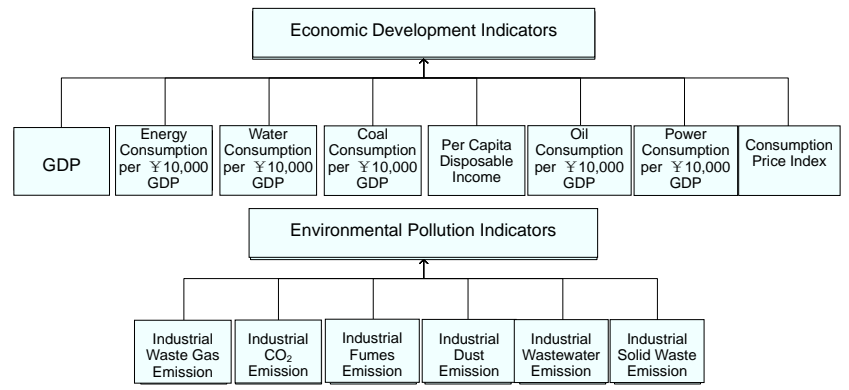

Figure 8. Selected indicators system of economic development and environment status.

Table 2. $A_{0}$ - Industrial Waste Gas Emission and $B_{0}$ - Indicator

\begin{tabular}{lll}
\hline Year & Regional GDP & Industrial Exhaust Emissions \\
\hline 2001 & 3707.96 & 3035.00 \\
2002 & 4315.00 & 2966.00 \\
2003 & 5007.21 & 3005.00 \\
2004 & 6033.21 & 3198.00 \\
2005 & 6969.52 & 3532.00 \\
2006 & 8117.78 & 3946.00 \\
2007 & 9846.81 & 4639.00 \\
2008 & 10879.00 & 5146.00 \\
\hline
\end{tabular}

\subsection{Model Development}

Details of the indicator set $A\left\{A_{0}, A_{1}, A_{2}, A_{3}, A_{4}, A_{5}\right\}$ are shown as follows: $A\left\{A_{0}\right.$-industrial waste gas emissions, $A_{1}$ industrial sulfur dioxide emissions, $A_{2}$-industrial smoke emi- ssions, $A_{3}$-industrial dust emissions, $A_{4}$-industrial wastewater emissions, $A_{5}$-industrial solid waste emissions $\}$. Typical economic indicators are selected as a research base, which is called indicators collection $B\left\{B_{0}, B_{1}, B_{2}, B_{3}, B_{4}, B_{5}, B_{6}, B_{7}\right\}$. Details are shown as follows: $B\left\{B_{0}\right.$-GDP, $B_{1}$-energy consumption per $¥ 10,000 \mathrm{GDP}, B_{2}$-water consumption per $¥ 10,000$ GDP, $B_{3}$-coal consumption per $¥ 10,000 \mathrm{GDP}, B_{4}$-disposable income per resident, $B_{5}$-oil consumption per $¥ 10,000 \mathrm{GDP}$, $B_{6}$-resident consumption price index, $B_{7}$-power consumption per $¥ 10,000$ GDP (Shen et al., 2012) \}.

\subsection{Preprocessing of Indicator Data with OLAP}

The element indicator $C_{00}$ represents the influence degree of $B_{0}$ on $A_{0}, C_{01}$ represents the influence degree of $B_{1}$ on $A_{0} \ldots \ldots C_{57}$ represent the influence degree of $B_{7}$ on $A_{5}$. The value of the elements of set $C$ has a significant impact (denoted as $Y$ ) or vague impact (denoted as $N$ ) (Chen and Wang, 2011). Indicator $A_{0}$ (industrial waste gas emission) and indicator $B_{0}$ (data of GDP) are shown in Table 2. Because the order of magnitude of different indicator data is relatively different, it is necessary to standardize the data (Stohr et al., 1999). Table 3 provides indicator $A_{0}$ and standardized indicator $B_{0}$.

Table 3. Indicator $A_{0}$ - Industrial Waste Gas Emissions and $B_{0}$-Standardized Indicator Data of GDP

\begin{tabular}{lll}
\hline Year & Regional GDP & Industrial Exhaust Emissions \\
\hline 2001 & 0.34 & 0.59 \\
2002 & 0.40 & 0.58 \\
2003 & 0.46 & 0.58 \\
2004 & 0.55 & 0.62 \\
2005 & 0.64 & 0.69 \\
2006 & 0.75 & 0.77 \\
2007 & 0.91 & 0.90 \\
2008 & 1.00 & 1.00 \\
\hline
\end{tabular}

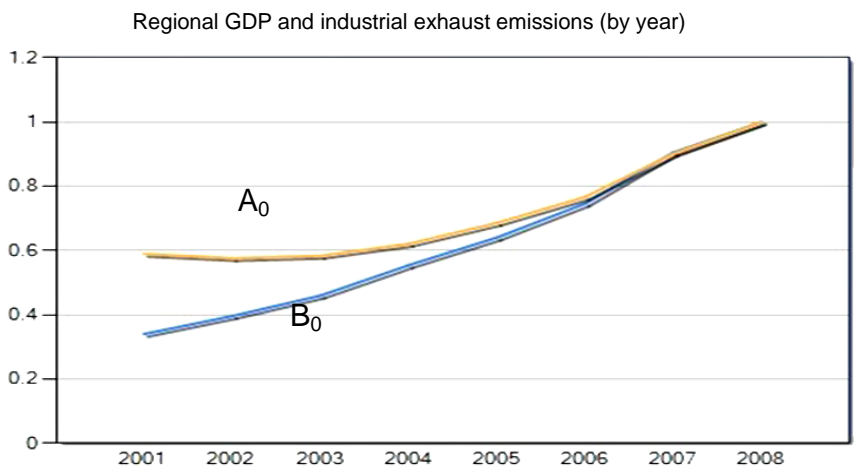

Figure 9. Impacts of GDP $\left(B_{0}\right)$ on Industrial Waste Gas Emission $\left(A_{0}\right)$.

The impact of indicator $B_{0}$ on indicator $A_{0}$ with OLAP is shown in Figure 9. The impact of the $B_{0}$ indicator on $A_{0}$ indicator is clear, so the value of $\mathrm{COO}$ element is $Y$. According to this method, the impact matrix is generated in Table 4. 
Table 4. Indicator Relationship Matrix

\begin{tabular}{lllllllll}
\hline$A$ & $B_{0}$ & $B_{1}$ & $B_{2}$ & $B_{3}$ & $B_{4}$ & $B_{5}$ & $B_{6}$ & $B_{7}$ \\
\hline$A_{0}$ & $\mathrm{Y}$ & $\mathrm{Y}$ & $\mathrm{N}$ & $\mathrm{Y}$ & $\mathrm{N}$ & $\mathrm{N}$ & $\mathrm{N}$ & $\mathrm{N}$ \\
$A_{1}$ & $\mathrm{~N}$ & $\mathrm{Y}$ & $\mathrm{N}$ & $\mathrm{Y}$ & $\mathrm{N}$ & $\mathrm{N}$ & $\mathrm{N}$ & $\mathrm{N}$ \\
$A_{2}$ & $\mathrm{~N}$ & $\mathrm{Y}$ & $\mathrm{N}$ & $\mathrm{Y}$ & $\mathrm{N}$ & $\mathrm{N}$ & $\mathrm{N}$ & $\mathrm{N}$ \\
$A_{3}$ & $\mathrm{~N}$ & $\mathrm{Y}$ & $\mathrm{N}$ & $\mathrm{Y}$ & $\mathrm{N}$ & $\mathrm{N}$ & $\mathrm{N}$ & $\mathrm{N}$ \\
$A_{4}$ & $\mathrm{~N}$ & $\mathrm{Y}$ & $\mathrm{Y}$ & $\mathrm{N}$ & $\mathrm{N}$ & $\mathrm{N}$ & $\mathrm{N}$ & $\mathrm{N}$ \\
$A_{5}$ & $\mathrm{~N}$ & $\mathrm{Y}$ & $\mathrm{N}$ & $\mathrm{Y}$ & $\mathrm{N}$ & $\mathrm{N}$ & $\mathrm{N}$ & $\mathrm{N}$ \\
\hline
\end{tabular}

Table 5. Description of Mathematical Model

\begin{tabular}{ll}
\hline Dependent variable & Industrial Waste Gas Emissions \\
\hline Equation & MOD_1 \\
\hline 1 & Linear \\
2 & Logarithm \\
3 & Quadratic \\
4 & Cubic \\
5 & Recombination \\
6 & Power \\
7 & S \\
8 & Increase \\
9 & Exponent \\
10 & Logistic \\
\hline Independent variable & GDP \\
\hline
\end{tabular}

In Table 4 , the subset of the set $C$ is $\left\{C_{00}, C_{01}, C_{03}, C_{11}\right.$, $\left.C_{13}, C_{21}, C_{23}, C_{31}, C_{33}, C_{41}, C_{42}, C_{51}, C_{53}\right\}$. The value of the 14 elements is $Y$. It shows that the degree of influence of the indicator is significant. This paper uses a mathematical model to further study the indicators.

\subsection{Quantitative Analysis of Indicators Relationship}

This study assumes that the influence function of indicator $B_{0}(\mathrm{GDP})$ on indicator $\mathrm{A}_{0}$ (industrial waste gas emissions) is $f_{01}$, namely: $A_{0}=f_{01}\left(B_{0}\right)$; the influence function of indicator $B_{1}$ (energy consumption per $¥ 10,000$ GDP) on indicator $A_{0}$ is $f_{02}$, namely: $A_{0}=f_{02}\left(B_{1}\right)$; the influence function of indicator $B_{3}$ (coal consumption per $¥ 10000$ GDP on indicator $A_{0}$ is $f_{03}$, namely: $A_{0}=f_{03}\left(B_{3}\right)$. Let the integrated influence function of indicators $B_{0}, B_{1}, B_{3}$ on $A_{0}$ be $g_{0}$, namely: $A_{0}=g_{0}\left(B_{0}, B_{1}\right.$, $B_{3}$ ). This study brings the relationship function between the two sides into the equation, leading to a functional model as shown below:

$$
\begin{aligned}
& A_{0}=g_{0}\left(f_{01}\left(B_{0}\right), f_{02}\left(B_{1}\right), f_{03}\left(B_{3}\right)\right) \\
& A_{1}=g_{1}\left(f_{11}\left(B_{1}\right), f_{12}\left(B_{3}\right)\right) \\
& A_{2}=g_{2}\left(f_{21}\left(B_{1}\right), f_{22}\left(B_{3}\right)\right) \\
& A_{3}=g_{3}\left(f_{31}\left(B_{1}\right), f_{32}\left(B_{3}\right)\right) \\
& A_{4}=g_{4}\left(f_{41}\left(B_{1}\right), f_{42}\left(B_{2}\right)\right) \\
& A_{5}=g_{5}\left(f_{51}\left(B_{1}\right), f_{52}\left(B_{3}\right)\right)
\end{aligned}
$$

Regarding the following mathematical calculation, only the specific calculation steps of the function $A_{0}=g_{0}\left(f_{01}\left(B_{0}\right)\right.$, $\left.f_{02}\left(B_{1}\right), f_{03}\left(B_{3}\right)\right)$ are given. The other functions are calculated in the similar way. Table 5 lists the selected mathematical model. When the two indicators are put into the equations above, the results are shown in Table 6 . In Table 6, the column shows the fitting value of every equation and the original data, and the two variables ( $R$ square and Sig.) explain the fitting value of the fitting selection equation from different aspects. When the $R$ square value is higher than 0.8 and the Sig value is less than 0.1 , the equation is feasible. This table above shows that the value of $R$ square of the cubic equation is 0.962 , the Sig value is 0 , the fitting value is to be the highest among all the selection equations, and thus the cubic equations is the most suitable one for simulating the function $f_{01}$. This study assumes that the amount of indicator $A_{0}$ (industrial waste gas emissions) is $y$, and the total value of indicator $B_{0}$ (GDP) is $x$, leading to the following function:

$f_{01}: y=-0.155 x_{3}+1.672 \mathrm{E}-5 x_{2}+1.213 \mathrm{E}-9 x+3347.275$

The influence function of indicator $B_{1}$ (energy consumption per $¥ 10,000 \mathrm{GDP}$ ) on indicator $A_{0}$ (industrial waste gas emissions) is $f_{02}$ :

$f_{02}: y=-21109.586 x_{3}+14155.174 x_{2}+-2994.539 x+$ 12997.987

The influence function of indicator $B_{3}$ (coal consumption per $¥ 10000 \mathrm{GDP}$ ) on indicator $A_{0}$ is $\mathrm{f}_{03}$ :

$f_{03}: y=-53255.479 x_{3}+78261.770 x_{2}+-37560.304 x+$ 14948.521

This study obtains the functions of $f_{01}, f_{02}$, and $f_{03}$, which indicates that $B_{0}, B_{1}$, and $B_{2}$ are influenced by $A_{0}$. Then three factors are integrated and the final function is obtained: $A_{0}=$ $g_{0}\left(f_{01}\left(B_{0}\right), f_{02}\left(B_{1}\right), f_{03}\left(B_{3}\right)\right)$.This study uses the multiple linear regression model to get the influence coefficients which indicate that $B_{0}, B_{1}$, and $B_{2}$ have a significant impact on $A_{0}$ :

$g_{0}=r_{1} * f_{01}\left(B_{0}\right)+r_{2} * f_{02}\left(B_{1}\right)+r_{3} * f_{03}\left(B_{3}\right)+n$

where $\mathrm{n}$ is a constant.

Table 7 shows the results of the multiple regression linear equation, the coefficient data and the examined data. It is indicated that, $r_{1}$ is $0.979, r_{2}$ is -2073.026, $r_{3}$ is 17081.566 and $n$ is -9247.749 .

$R_{i}=\left\{\begin{array}{c}0.979 \\ -2073.026 \\ 17081.566\end{array}\right\}$

$g_{0}=0.979 f_{01}+-2073.026 f_{02}+17081.566 f_{03}+-9247.749$ 
Table 6. Summary of Fitting Degree and Estimated Parameters of Function $\mathrm{f}_{01}$

\begin{tabular}{|c|c|c|c|c|c|c|}
\hline \multirow[t]{2}{*}{ Equation } & \multicolumn{2}{|l|}{ Summary } & \multicolumn{4}{|l|}{ Parameters } \\
\hline & $\mathrm{R}$ square & Sig. & Constant & $b 1$ & $b 2$ & $b 3$ \\
\hline linear & .760 & .000 & 2512.641 & .192 & & \\
\hline logarithm & .551 & .002 & -3011.728 & 777.920 & & \\
\hline quadratic & .961 & .000 & 3504.097 & -.269 & $3.878 \mathrm{E}-5$ & \\
\hline cubic & .962 & .000 & 3347.275 & -.155 & $1.672 \mathrm{E}-5$ & 1.213E-9 \\
\hline recombination & .766 & .000 & 2665.816 & 1.000 & & \\
\hline power & .565 & .002 & 628.438 & .203 & & \\
\hline $\mathrm{S}$ & .367 & .022 & 8.304 & -582.953 & & \\
\hline increase & .766 & .000 & 7.888 & 4.975E-5 & & \\
\hline exponent & .766 & .000 & 2665.816 & 4.975E-5 & & \\
\hline Logistic & .766 & .000 & .000 & 1.000 & & \\
\hline
\end{tabular}

Table 7. Coefficient Data and Examined Data of Function $g_{0}$

\begin{tabular}{|c|c|c|c|c|c|}
\hline \multirow{2}{*}{ Model } & \multicolumn{2}{|c|}{ Non-standardized coefficient } & \multirow[t]{2}{*}{ Standardized coefficient } & \multirow[t]{2}{*}{$t$} & \multirow[t]{2}{*}{ Sig. } \\
\hline & $B$ & Standardized error & & & \\
\hline constant & -9247.749 & 2435.003 & & -3.798 & .003 \\
\hline GDP & .979 & .160 & 4.444 & 6.136 & .000 \\
\hline energy consumption per $¥ 10,000$ GDP & -2073.026 & 712.147 & -1.706 & -2.911 & .016 \\
\hline coal consumption per $¥ 10,000$ GDP & 17081.566 & 4072.935 & 5.202 & 4.194 & .002 \\
\hline
\end{tabular}

$g_{0}=0.979\left(-0.155 B_{03}+1.672 \mathrm{E}-5 B_{02}+1.213 \mathrm{E}-9 B_{0}+3347.275\right)$

$+(-2073.026)\left(-21109.586 B_{13}+14155.174 B_{12}+-2994.539 B_{1}+\right.$ $12997.987)+17081.566\left(-53255.479 B_{33}+78261.770 B_{32}+\right.$ $\left.\left(-37560.304 B_{3}\right)+14948.521\right)+(-9247.749)$

$$
\begin{aligned}
& g_{0}=(0.979,-2073.026,17081.566) \\
& \left\{\begin{array}{c}
-0.155 B_{0}{ }^{3}+1.672 E-5 B_{0}{ }^{2}+1.213 E-9 B_{0}+3347.275 \\
-21109.586 B_{1}^{3}+14155.174 B_{1}{ }^{2}+-2994.539 B_{1}+12997.987 \\
-53255.479 B_{3}^{3}+78261.770 B_{3}{ }^{2}+-37560.304 B_{3}+14948.521
\end{array}\right\}
\end{aligned}
$$$$
-9247.749
$$

Three indicators (GDP, energy consumption per ¥10000 GDP and coal consumption per $¥ 10000$ GDP) have obvious influences on industrial waste gas emission. According to Beijing's 10-year indicators, this study provides the influence function of these three indicators on industrial waste gas emission.

\section{Conclusions}

This study creates an OLAP multi-indicator relational model, which can be applied to reflect the relationship among economy, energy and environment in the specific area, and to support the cooperation among energy-sector, economy-sector and environment-sector. This study obtains the relational function between economy (set $A$ ) and environment (set $B$ ) indicators through our model. For example, the interactive effect relations between set $A$ and set $B$ : $A_{1}=g\left(f_{1}\left(B_{1}\right), f_{2}\left(B_{3}\right)\right.$, $f_{3}\left(B_{5}\right)$ ). The synthesized effect function of the three indicators $\left(B_{1}, B_{3}, B_{5}\right)$ on indicator $A_{1}$ is $g$, through this function. This study analyzes the effects of $B_{1}, B_{2}$, and $B_{3}$ on $A_{1}$, and then counts the effects of indicator $A_{1}$ on indicators $B_{1}, B_{3}$, and $B_{5}$.
Acknowledgments. The work described in this paper was supported by Beijing Natural Science Foundation (Project Number: 9122021) and Beijing Municipal Commission of Education.

\section{References}

Bouwman, M.J. (1983). Human diagnostic reasoning by computer: an illustration from financial analysis, Man. Sci., 29(6), 653-672. http://dx.doi.org/10.1287/mnsc.29.6.653

Chen, Y.H., and Wang, G.Y. (2011). Energy consumption, environmental pollution and economic growth Empirical Analysis-Taking Jiangsu Province as an example, Theor. Constr., 6(5), 58-60.

Fang, G.C., Tian, L.X., Sun, M., Fu, M. (2012). Analysis and application of a novel three-dimensional energy-saving and emissionreduction dynamic evolution system, Energy, 40(1), 291-299. http: //dx.doi.org/10.1016/j.energy.2012.01.071

Li, Y., Zhen, Y., Guo, T.T., and Zhou, J. (2011). Study of the Resource Utilization Management of Construction Waste, Env. Sci., 11 (B), 869-873. http://dx.doi.org/10.1016/j.proenv.2011.12.133

Liu, K., Guo, W.Y., Shen, X.L., and Tan, Z.F. (2012a). Research on the forecast model of electricity power industry loan based on GABP neural network, Energ. Proc., 14(1), 1918-1924. http://dx.doi. org/10.1016/j.egypro.2011.12.1188

Liu, K., Shen, X.L., and Ji, Y.M. (2012b). Multiple linear regression model based research on relationship between energy consumption and economic growth, Adv. Mat. Res., 361(1), 1296-1299. http://dx. doi.org/10.4028/www.scientific.net/AMR.361-363.1296

Liu, N. (2008). Research and system development of based on OLAP technology. North China Electric Power University, BJ, China.

Lv, L.H., Chai, F.H., Luo, H., and Zhang, Z. (2011). Power-environment-economic complex system optimization, Ind. Techn. Econ., 10(1), 8-13.

Ma, Y.Y. (2012). Relationship research between Economic growth and the evolution of environmental pollution-the case of Dalian. Wuhan, Univ. Sci. Techn., 5(2), 88-92.

Mike, G., and Tim, S. (2001). SQL Server Developer Guide OLAP (online analytical processing). Electronics Industry Press, BJ, China.

Ouyang, J.L., Wang, C.Y., Li, H.F., and Hokao, Kazunori. (2011). A 
methodology for energy-efficient renovation of existing residential buildings in China and case study, Energ. Build., 43(9), 2203-2210. http://dx.doi.org/10.1016/j.enbuild.2011.05.005

Schoots, K., Ferioli, and Kramer, F. (2008). Learning curves for hydrogen production technology: An assessment of observed cost reductions, J. Hydr. Energ., 33(11), 2630-2645. http://dx.doi.org /10.1016/j.ijhydene.2008.03.011

Shaligram, P. (2007). An econometric analysis of energy consumption in Nepal, En. Pol., 5(1), 15-19. http://dx.doi.org/10.1016/j. enpol.2005.11.004

Shen, X.L., Bai, J.J., Shen, Y.S., and Tan, Z.F. (2010). Applied online analytical technology to study the regional energy-economy-environment indicators correlation, Energ. Techn., 31(4), 202-234.

Shen, Y.S., Tan, Z.F., Zhao, Y.H., Hu, Q.H., and Zhang, C. (2012). Inter-regional power-generation economic exchange analysis model under environmental constraints, Adv. Mat. Res., 361(2), 15101523.

Stohr, T., Muller, R., and Rahm, E. (1999). An Integrative and Uniform Model for Metadata Management in Data Warehousing Environments, Proc., the International Workshop on Design and Management of Data Warehouses, Heidelberg, Germany, 168-200.

Tan, Z.F., Hou, J.C., Xie, P.J., and Han, J.H. (2009). Urban energyeconomic-environmental development policy analysis model. Education. Publishing. House., HB, China.

Tony, B., and Mike, B. (2003). SQL Server 2000 data warehouse and Analysis Services. China Electric Power Press, BJ, China.

Wang, H.Z. (2010). Research and application of OLAP and forecasting \&warning technology on 3E-sustainable development platform. North China Electric Power University, BJ, China.

Wang, H.Z., Shen, X.L., and Liu, K. (2009a). Research on forecast and early-warning model of energy-economy-environment system, Proc., International Joint Conference on Artificial Intelligence, California, USA, 417-420. http://dx.doi.org/10.1109/JCAI.2009.98

Wang, M.Y., You, L.L., Liu, K., and Shen, X.L. (2011a). The model library construction based on energy-economy-environment sustainnable development research platform, Env. Transp. Engineer., 5530-5533.

Wang, X.Q., and Shen, X.L. (2009). Building a Web-based Decision Support System for Sustainable Development of Energy, Economy and Environment, Proc., International Conference on Signal Processing Systems, Singapore, 504-510.

Wang, X.Q., Shen, X.L., and Tan, Z.F. (2009b). Building a Webbased Decision Support System for Sustainable Development of Energy, Economy and Environment, Proc., International Conference on Signal Processing Systems, Singapore, 81-84.

Wang, X.Q., Shen, X.L., Tan, Z.F., Yang, J.J., and Zhou, N.H. (2009c). Research and Application of a Data-driven Platform for Sustainable Development of Energy, Economy and Environment, Proc., the International Conference on Environment and Computer Science, Dubai, UAE, 121-124.

Wang, Y.F., and Liu, X.B. (2011b). The relationship between environmental pollution and economic growth, On. Res., 9(1), 136 -137.

Yang, M., Shen, X.L., and Tan, Z.F. (2010). Research and Application of Beijing's Energy Consumption and Economic Development Based on OLAP, Comp. Appl. Syst. Mod., 5(2), 39-45.

Yin, H.J, and Liu, E. (2003). Social statistics soft of SPSS for window Concise Guide. Social Science Academic Press, BJ, Chin.

You, L.L., Wang, M.Y., Shen, X.L., and Guo, W.Y. (2011). The gray correlation research on the sustainable development of Beijing and industrial structure based on 3EDSS, Adv. Mat. Res., 36(1), 12111219. http://dx.doi.org/10.4028/www.scientific.net/AMR.361-363. 1153

Zhang, H.B., Li, M., and Chen, X. (2009). The information-based research of energy management to saving energy and reducing pollutant, YN. Univ. J., 31 (S2), 155-158.

Zhang, Y.Y. (2010). Design and Implementation of business decisionmaking system based on OLAP technology, Commun. Man. and Techn., 25(1), 25-27. 